\title{
Newer Endodontic irrigation devices: An update
}

\author{
Dr. Deenadayalan Elumalai ${ }^{1}$, Dr. Ashok Kumar ${ }^{2}$, Dr. Rajendra K Tewari ${ }^{2}$, \\ Dr. Surendra K Mishra ${ }^{2}$, Dr. Huma Iftekhar ${ }^{3}$, Dr. Sharique Alam ${ }^{3}$, \\ Dr. Mukhtar Andrabi ${ }^{3}$ \\ ${ }^{I}$ Resident Doctor, Department of Conservative Dentistry and Endodontics, Aligarh Muslim University, Aligarh, \\ $U P$, India. \\ ${ }^{2}$ Professor, Department of Conservative Dentistry and Endodontics, Aligarh Muslim University, Aligarh, UP, \\ India. \\ ${ }^{3}$ Assistant Professor, Department of Conservative Dentistry and Endodontics, Aligarh Muslim University, \\ Aligarh, UP, India.
}

\begin{abstract}
The ultimate aim of endodontic therapy is thorough debridement of root canal system. The aim of this review is to give a brief description of endodontic irrigation devices and their efficacy in root canal therapy. Recently developed irrigation devices and their application mode also discussed. Mechanism of these devices and the phenomenon that governs the irrigation efficacy discussed briefly.
\end{abstract}

Key Words: Newer irrigation devices, Endodontic irrigation, EndoVac, RinsEndo, Ultrasonic irrigation

\section{Introduction}

The essential for endodontic success is requires removal of vital and necrotic remnants of pulp tissues, microorganisms, and microbial toxins from the root canal system. ${ }^{1,}{ }^{2}$ This can be achieved through chemomechanical debridement but because of the intricate nature of root canal anatomy it is impossible to shape and clean the root canal completely. ${ }^{3}$ All the instrumentation systems as well as current advancements in the instruments like nickel- titanium instruments and rotary can only clean the central body of the canal. Rest of the canal structures like canal fins, isthmi, and cul-de-sacs are untouched after completion of the preparation. ${ }^{4}$ These areas are might be the potential place for containing tissue debris, microbes, and their by-products which might prevent close adaptation of the obturation material and result in persistent periradicular inflammation. ${ }^{5}$ Irrigation allows for cleaning beyond what might be achieved by root canal instrumentation alone so it is an essential part of root canal debridement. Till date none of the irrigant posses ideal quality that is why in contemporary endodontic practice, dual irrigants such as sodium hypochlorite $(\mathrm{NaOCl})$ with ethylenediaminetetraacetic acid (EDTA) or chlorhexidine (CHX) are often used as initial and final rinses to complement the shortcomings that are associated with the use of a single irrigant. Irrigants must be brought into direct contact with the entire canal wall surfaces for effective action particularly for the apical portions of small root canals. Various methods have been developed in order to provide effective delivery. These systems might be divided into 2 broad categories, manual agitation techniques and machine-assisted agitation devices. The objective of this review was to present an overview of contemporary irrigation methods available in endodontics.

\section{Manual irrigation techniques}

Manual irrigation system using needles is still widely accepted by both general practitioners and endodontists. In this technique the dispensing of an irrigant into a canal through needles/cannulas of variable gauges, either passively or with agitation. The agitation might be achieved by moving the needle up and down the canal space. The design of these needles can be closed-ended, side-vented channels.

\section{Max-i-probe}

Max-i-probe is a modified design of regular manual irrigation needles with a well-rounded, close tip and side-port dispersal. This needle is available is available in a wide range of gauges from 21 to 30 gauge. The luer lock connector provides a secure attachment and easy removal from any disposable syringe. The manufacturer claimed that the rounded tip prevents the risk of perforating the apex and allows for safe irrigation of the entire length of the root canal. The dispersal of the irrigating solution through the side-port in the cannula creates a unique upward turbulent motion, which thoroughly irrigates the root canal preparation but prevents solution and debris from being expressed through the periapical foramen.

The manual needle irrigation systems allow good control of needle depth and the volume of irrigant that is flushed through the canal. ${ }^{6}$ However when conventional syringe needle irrigation was used, the irrigating solution was delivered only $1 \mathrm{~mm}$ deeper than the tip of the needle. ${ }^{7}$ It is difficult to access the apical third of the canal because the needle tip is often located in the coronal third of a narrow canal or, at best, the middle third of 
a wide canal. Nevertheless, the mechanical flushing action created by conventional hand-held syringe needle irrigation is relatively weak. After conventional syringe needle irrigation, inaccessible canal extensions and irregularities are likely to harbour debris and bacteria, thereby making thorough canal debridement difficult. ${ }^{8}$ These drawbacks lead to the quest for the development of machine assisted irrigation systems.

\section{NaviTip Fx}

NaviTip Fx is a 30-gauge irrigation needle covered with a brush was introduced commercially by Ultradent company. Brush is an adjunct that has been designed for debridement of the canal walls or agitation of root canal irrigant. NaviTip FX needle gave improved cleanliness in coronal third when compared to brushless NaviTip needle. Nevertheless the differences in the apical and middle thirds were not statistically significant. ${ }^{9}$ NaviTip FX brush bristles may dislodge inside the canal irregularities due to the friction, because of its radiolucent nature it is very difficult to identify radiographically and even with the use of a surgical microscope. ${ }^{6}$

\section{The Quantec-E irrigation system}

The Quantec-E irrigation system was introduced by SybronEndo company is a selfcontained fluid delivery unit that is attached to the Quantec-E Endo System. It uses a pump console, 2 irrigation reservoirs, and tubing to provide continuous irrigation during rotary instrumentation. It has been proposed that continuous irrigant agitation during active rotary instrumentation would generate an increased volume of irrigant, increase irrigant contact time, and facilitate greater depth of irrigant penetration inside the root canal. This should result in more effective canal debridement compared with syringe needle irrigation. However studies conducted by Setlock et $\mathrm{al}^{10}$ and Walters et $\mathrm{al}^{11}$ proved that Quantec-E irrigation did result in cleaner canal walls and more complete debris and smear layer removal in the coronal third of the canal walls and there was no significant difference between standard syringe needle irrigation and irrigation with the Quantec-E pump.

\section{The Vibringe System}

The Vibringe System an irrigation device that combines manual delivery and sonic activation of the solution has been introduced by a Dutch company Vibringe B. V. The Vibringe is a cordless handpiece that fits in a special disposable 10-mL Luer-Lock syringe that is compatible with every irrigation needle. The Vibringe allows delivery and sonic activation of the irrigating solution in one step. It employs a 2-piece syringe with a rechargeable battery. The irrigant is sonically activated, as is the needle that attaches to the syringe. Rödig et al ${ }^{12}$ evaluated the efficacy of vibringe system they concluded that vibringe demonstrated significantly better results than syringe irrigation in the apical root canal third in removing debris. However it was not as effective as the passive ultra sonic irrigation.

\section{The EndoActivator System}

The EndoActivator System is a more recently introduced sonically driven canal irrigation system by Dentsply. It consists of a portable handpiece and 3 types of disposable polymer tips of different sizes. These tips are claimed to be strong and flexible and do not break easily. Because they are smooth, they do not cut dentin. Vibrating the tip, in combination with moving the tip up and down in short vertical strokes, synergistically produces a powerful hydrodynamic phenomenon. This might be operated 10,000 cycles per minute (cpm) has been shown to optimize debridement and promote disruption of the smear layer and biofilm. ${ }^{13}$ The EndoActivator System was reported to be able to effectively clean debris from lateral canals, remove the smear layer, and dislodge clumps of simulated biofilm within the curved canals of molar teeth. ${ }^{13}$

\section{Ultrasonic Irrigation}

Ultrasonic irrigation can be used as an intermittent irrigation or a continuous ultrasonic irrigation. In intermittent flushed ultrasonic irrigation, the irrigant is delivered to the root canal by a syringe needle. The irrigant is then activated with the use of an ultrasonically oscillating instrument.

Nusstein developed a needle-holding adapter to an ultrasonic handpiece. ${ }^{14}$ During ultrasonic activation, a 25-gauge irrigation needle is used instead of an endosonic file. This enables ultrasonic activation to be performed at the maximum power setting without causing needle breakage. In this continuous ultra sonic irrigation system the needle is simultaneously activated by the ultrasonic handpiece, while an irrigant is delivered from intravenous tubing connected via a Luer-lok to an irrigation-delivering syringe. The irrigant can thus be delivered apically through the needle under a continuous flow instead of being intermittently replenished from the coronal access opening. Various studies demonstrated that 1 minute of continuous ultrasonic irrigation produced significantly cleaner canals and isthmi in both vital and necrotic teeth. ${ }^{15,16}$ 


\section{The EndoVac System}

The EndoVac apical negative pressure irrigation system has been introduced by Discus Dental Company. It has three components: The Master Delivery Tip, MacroCannula and MicroCannula. The Master Delivery Tip simultaneously delivers and evacuates the irrigant. The MacroCannula is used to suction irrigant from the chamber to the coronal and middle segments of the canal. The MacroCannula or MicroCannula is connected via tubing to the high-speed suction of a dental unit. The Master Delivery Tip is connected to a syringe of irrigant and the evacuation hood is connected via tubing to the high-speed suction of a dental unit. ${ }^{17}$ The plastic macrocannula has a size 55 open end with a .02 taper and is attached to a titanium handle for gross, initial flushing of the coronal part of the root canal. The size 32 stainless steel microcannula has 4 sets of 3 laser-cut, laterally positioned, offset holes adjacent to its closed end. This is attached to a titanium finger-piece for irrigation of the apical part of the canal by positioning it at the working length. The microcannula can be used in canals that are enlarged to size 35 or larger. During irrigation, the delivery/evacuation tip delivers irrigant to the pulp chamber and siphons off the excess irrigant to prevent overflow. The cannula in the canal simultaneously exerts negative pressure that pulls irrigant from its fresh supply in the chamber, down the canal to the tip of the cannula, into the cannula, and out through the suction hose. Thus, a constant flow of fresh irrigant is being delivered by negative pressure to working length. Apical negative pressure has been shown to enable irrigants to reach the apical third and help overcome the issue of apical vapor lock. ${ }^{18,19}$

In studies comparing the efficacy of EndoVac with other systems like passive ultrasonic, F File, the Manual Dynamic Max-I-Probe, the Pressure Ultrasonic, and the EndoActivator revealed only the EndoVac was capable of cleaning $100 \%$ of the isthmus area. ${ }^{20,21,22}$ Apart from being able to avoid air entrapment, the EndoVac system is also advantageous in its ability to safely deliver irrigants to working length without causing their undue extrusion into the periapex, thereby avoiding sodium hypochlorite incidents. It is important to note that it is possible to create positive pressure in the pulp canal if the Master Delivery Tip is misused, which would create the risk of a sodium hypochlorite incident. The manufacturer's instructions must be followed for correct use of the Master Delivery Tip.

\section{The RinsEndo System}

The RinsEndo system irrigates the canal by using pressure-suction technology developed by Durr Dental Co. Its components are a handpiece, a cannula with a $7 \mathrm{~mm}$ exit aperture, and a syringe carrying irrigant. The handpiece is powered by a dental air compressor and has an irrigation speed of $6.2 \mathrm{ml} / \mathrm{min}$. With this system, $65 \mathrm{~mL}$ of a rinsing solution oscillating at a frequency of $1.6 \mathrm{~Hz}$ is drawn from an attached syringe and transported to the root canal via an adapted cannula. During the suction phase, the used solution and air are extracted from the root canal and automatically merged with fresh rinsing solution. The pressure-suction cycles change approximately 100 times per minute. ${ }^{6}$ The manufacturer of RinsEndo claims that the apical third of the canal might be effectively rinsed, with the cannula restricted to the coronal third of the root canal because of the pulsating nature of the fluid flow. McGill et al ${ }^{23}$ evaluated the effectiveness of RinseEndo system in a split tooth model. They found to be less effective in removing the stained collagen from root canal walls when compared with manual-dynamic irrigation by hand agitation of the instrumented canals with well-fitting gutta-percha points.

\section{Photo Activated Disinfection}

Recently the concept of photo activated disinfection (PAD) in endodontic irrigation has been introduced in order to minimize or eliminate residual bacteria in the root canal. PAD technique employs a nontoxic dye, termed a photosensitizer (PS), and low intensity visible light which, in the presence of oxygen, combine to produce cytotoxic species. The principle on which it operates is that PS molecules attach to the membrane of the bacteria. Irradiation with light at a specific wavelength matched to the peak absorption of the PS leads to the production of singlet oxygen, which causes the bacterial cell wall to rupture, killing the bacteria. $^{24,25}$ PAD is not only effective against bacteria, but also against other micro-organisms including viruses, fungi, and protozoa. FotoSan is the PAD device recently introduced by CMS Dental. The PS is a watery solution of toluidine blue $\mathrm{O}$ (TBO) that attaches to the membranes of microorganisms and binds itself to their surface, absorbs energy from the light and then releases this energy to oxygen (O2), which is transformed into highly reactive oxygen species (ROS), such as oxygen ions and radicals. The manufacturer's protocol indicates that, after canal preparation, the canal have to be inoculated with the PS solution, which is left in situ for a fixed period of time (60 seconds) to permit the solution to come into contact the root canal and irradiation have to be carried out for 30 seconds in each canal. Schlafer et $\mathrm{al}^{26}$ found that PAD gave a strong reduction of the number of viable endodontic pathogens both in planktonic suspension and in root canals. 


\section{Ozone based Delivery System}

Ozone is a triatomic molecule consisting of three oxygen atoms. It is applied to oral tissues in the forms of ozonated water, ozonated olive oil and oxygen/ozone gas. It is unstable and dissociates readily back into oxygen $(\mathrm{O} 2)$, thus liberating so-called singlet oxygen $(\mathrm{O} 1)$, which is a strong oxidizing agent which further impose the deleterious effect on microorganisms. Various delivery systems available for endodontic irrigation like Neo Ozone Water-S unit, HealOzone (Kavo) unit, the OzoTop unit. Nagayoshi et al. ${ }^{27}$ found that ozonated water $(0.5-4 \mathrm{mg} / \mathrm{L})$ was highly effective in killing both gram positive and negative micro-organisms.

Gram negative bacteria, such as Porphyromonas $(P$.) endodontalis and $P$. gingivalis were substantially more sensitive to ozonated water than gram positive oral streptococci and C. albicans in pure culture. Notably, when the specimen was irrigated with sonication, ozonated water had nearly the same antimicrobial activity as $2.5 \% \mathrm{NaOCl} .{ }^{28}$ Ozone works best when there is less organic debris remaining. Therefore, the recommendation is to use either ozonated water or ozone gas at the end of the cleaning and shaping process. Ozone is effective when it is used in sufficient concentration, for an adequate time. Ozone will not be effective if too little dose of ozone is delivered or it is not delivered appropriately. ${ }^{29}$

\section{The VATEA system}

The VATEA system is an irrigation device which is an integral part of Self Adjusting file rotary system (SAF). The VATEA system is a self-contained, fluid delivery unit intended to be attached to dental handpieces to deliver irrigation during endodontic procedures. During the endodontic treatment, irrigation solution is pumped from the VATEA's $400 \mathrm{ml}$ reservoir. The irrigant is delivered via a disposable silicone tube to the endodontic file. The flow of irrigant is toggled using a foot pedal. The operator can adjust the flow rate from 1$10 \mathrm{ml} / \mathrm{min}$ by using the -/+ push buttons located on the control panel. A recent independent study by Prof. Jose Siqueira from Estácio de Sá University, Brazil, indicated that in oval canals the SAF SYSTEM was found superior to rotary $\mathrm{Ni}-\mathrm{Ti}$ files used with needle irrigation $(\mathrm{NaOCl})$.

\section{Phenomenon related to Endodontic Irrigation}

Acoustic microstreaming and Cavitation are the two major hydrodynamic phenomenon associated with Ultrasonic irrigation. Acoustic microstreaming is defined as the movement of fluids along cell membranes, which occurs as a result of the ultrasound energy creating mechanical pressure changes within the tissue. Cavitation is defined as the formation and collapse of gas- and vapor-filled bubbles or cavities in a fluid. The cavitation is minimal and is restricted to the tip. The acoustic streaming effect, however, is significant. In fact, the irrigant is activated by the ultrasonic energy imparted from the energized instruments, producing acoustic streaming and eddies. Acoustic streaming, as described by Ahmad et al ${ }^{30}$ has been shown to produce sufficient shear forces to dislodge debris in instrumented canals. When files were activated with ultrasonic energy in a passive manner, acoustic streaming was sufficient to produce significantly cleaner canals compared with hand filing alone. When debridement comes to the apical third of the root canal it is important to know one more phenomenon called the vapour lock effect. Air entrapment by an advancing liquid front in closed-end microchannels is a well-recognized physical phenomenon. Since roots are surrounded by the periodontium, and unless the root canal foramen is open, the root canal behaves like a close-ended channel. This produces an apical vapor lock effect that resists displacement during instrumentation and final irrigation, thus preventing the flow of irrigant into the apical region and adequate debridement of the canal system. Apical vapour lock also results in gas entrapment at the apical third. During irrigation, sodium hypochlorite $(\mathrm{NaOCl})$ reacts with organic tissue and forms micro gas bubbles which consist of ammonia and carbon dioxide. These gas mixtures further coalesce into an apical vapour lock with subsequent instrumentation. The apical vapour lock cannot be displaced within a clinically relevant time frame through simple mechanical actions, it prevents further irrigants from flowing into the apical region ${ }^{17}$. Acoustic microstreaming and cavitation are limited to liquids and have no effect inside the vapour lock. Acoustic microstreaming or cavitation is only possible in fluids/liquids, not in gases. Therefore, as previously mentioned, it is physically impossible for acoustic microstreaming and/or cavitation to disrupt the apical vapor lock ${ }^{17}$. The only method yet discovered to eliminate the apical vapor lock is to evacuate it via apical negative pressure. This method has also been proven to be safe because it always draws irrigants to the source via suction down the canal and simultaneously away from the apical tissue in abundant quantities. ${ }^{31}$

\section{Summary}

Various irrigation devices have been developed to give the effective cleaning and superior debris removal in order to replace the older needle irrigation method. Many clinical studies have reported the higher efficacy in effective microbial count. However, there is no high level of evidence that correlates the clinical efficacy of these devices with better treatment outcomes. Nevertheless, due to the safety factors, capacity of high volume irrigant delivery and ease of application the newer irrigation devices may change the insight of conventional endodontic treatment. 


\section{References}

[1]. Wong R. Conventional endodontic failure and retreatment. Dent Clin North Am 2004;48:265-89.

[2]. Basmadjian-Charles CL, Farge P, Bourgeois DM, Lebrun T. Factors influencing the long-term results of endodontic treatment: a review of the literature. Int Dent J 2002; 52:81-6.

[3]. Ferreira RB, Alfredo E, Porto de Arruda M, Silva Sousa YT, Sousa-Neto MD. Histological analysis of the cleaning capacity of nickel-titanium rotary instrumentation with ultrasonic irrigation in root canals. Aust Endod J 2004;30:56-8

[4]. Walton RE. Histologic evaluation of different methods of enlarging the pulp canal space. J Endod 1976;2:304-11.

[5]. Naidorf IJ. Clinical microbiology in endodontics. Dent Clin North Am 1974;18: 329-44.

[6]. Gu LS, Kim JR, Ling J, Choi KK, Pashley DH, Tay FR. Review of contemporary irrigant agitation techniques and devices. J Endod. 2009;35(6):791-804.

[7]. Ram Z. Effectiveness of root canal irrigation. Oral Surg Oral Med Oral Pathol 1977; 44:306-12.

[8]. Wu MK, Wesselink PR. A primary observation on the preparation and obturation of oval canals. Int Endod J 2001;34:137-41.

[9]. Al-Hadlaq SM, Al-Turaiki SA, Al-Sulami U, Saad AY. Efficacy of a new brush-covered irrigation needle in removing root canal debris: a scanning electron microscopic study. J Endod 2006;32:1181-4.

[10]. Setlock J, Fayad MI, BeGole E, Bruzick M. Evaluation of canal cleanliness and smear layer removal after the use of the Quantec-E irrigation system and syringe: a comparative scanning electron microscope study. Oral Surg Oral Med Oral Pathol Oral Radiol Endod 2003;96:614-7.

[11]. Walters MJ, Baumgartner JC, Marshall JG. Efficacy of irrigation with rotary instrumentation. J Endod 2002;28:837-9.

[12]. Rödig T, Bozkurt M, Konietschke F, Hülsmann M. Comparison of the Vibringe system with syringe and passive ultrasonic irrigation in removing debris from simulated root canal irregularities. J Endod 2010;36:1410-1413.

[13]. Caron G. Cleaning efficiency of the apical millimeters of curved canals using three different modalities of irrigant activation: an SEM study. Paris VII University, Paris, France: Masters thesis; 2007.

[14]. Nusstein J. Ultrasonic dental device. Washington, DC: United States Patent 6,948,935; 2005.

[15]. Gutarts R, Nusstein J, Reader A, Beck M. In vivo debridement efficacy of ultrasonic irrigation following hand-rotary instrumentation in human mandibular molars. J Endod 2005;31:166-70.

[16]. Burleson A, Nusstein J, Reader A, Beck M. The in vivo evaluation of hand/rotary/ ultrasound instrumentation in necrotic, human mandibular molars. J Endod 2007; 33:782-7.

[17]. Schoeffel GJ. The EndoVac method of endodontic irrigation: part 2-efficacy. Dent Today. 2008;27:82,84,86-87.

[18]. Nielsen BA, Baumgartner JC. Comparison of the endovac system to needle irrigation of root canals. J Endod. 2007;33:611-5.

[19]. Shin SJ, Kim HK, Jung IY, Lee CY, Lee SJ, Kim E. Comparison of the cleaning efficacy of a new apical negative pressure irrigating system with conventional irrigation needles in the root canals. Oral Surg Oral Med Oral Pathol Oral Radiol Endod. 2010 Mar;109(3):479-84.

[20]. Gutarts R, Nusstein J, Reader A, Beck M. In vivo debridement efficacy of ultrasonic irrigation following handrotary instrumentation in human mandibular molars. J Endod. 2005;3:166-170.

[21]. Klyn SL, Kirkpatrick TC, Rutledge RE. In vitro comparisons of debris removal of the EndoActivator System, the F File, ultrasonic irrigation, and $\mathrm{NaOCl}$ irrigation alone after handrotary instrumentation in human mandibular molars. J Endod. 2010;36(8):1367-71.

[22]. Susin L, Parente JM, Loushine RJ, et al. Canal and isthmus debridement efficacies of two irrigant agitation techniques in a closed system. Int Endod J. 2010;43(12):1077-90.

[23]. McGill S, Gulabivala K, Mordan N, Ng YL. The efficacy of dynamic irrigation using a commercially available system (RinsEndo) determined by removal of a collagen 'bio-molecular film' from an ex vivo model. Int Endod J 2008;41: 602-8.

[24]. Burns T, Wilson M, Pearson GJ. Sensitisation of cariogenic bacteria to killing by light from a helium-neon laser. J Med Microbiol. 1993;38(6):401-405.

[25]. Bonsor SJ, Nichol R, Reid TMS, Pearson GJ. Microbiological evaluation of photo-activated disinfection in endodontics (An in vivo study). Br Dent J. 2006;200(6):337-341

[26]. Schlafer S, Vaeth M, Horsted-Bindslev P, Frandsen EVG. Endodontic photoactivated disinfection using a conventional light source: an in vitro and ex vivo study. Oral Surg Oral Med Oral Pathol. 2010;109(4):634-641.

[27]. Nagayoshi M, Fukuizumi T, Kitamura C, Yano J, Terashita M, Nishihara T. Efficacy of ozone on survival and permeability of oral microorganisms. Oral MicrobiolImmunol. 2004;19(4):240-6.

[28]. Arita M, Nagayoshi M, Fukuizumi T, Okinaga T, Masumi S, Morikawa M, et al. Microbicidal efficacy of ozonated water against Candida albicans adhering to acrylic denture plates. Oral Microbiollmmunol 2005;20:206-10.

[29]. Huth KC, Quirling M, Maier S, Kamereck K, Alkhayer M, Paschos E, et al. Effectiveness of ozone against endodontopathogenic microorganisms in a root canal biofilm model. IntEndod $\mathrm{J}$ 2009;42:3-13.

[30]. Ahmad M, Pitt Ford TR, Crum LA. Ultrasonic debridement of root canals: acoustic streaming and its possible role. J Endod 1987;13:490-9.

[31]. Schoeffel GJ. The EndoVac method of endodontic irrigation: Part 4, Clinical Use. Dent Today. 2009;28(6):64, 66-67. 